\title{
Majorana Demonstrator Bolted Joint Mechanical and Thermal Analysis
}

\author{
E Aguayo \\ DJ Reid \\ JE Fast
}

June 2012

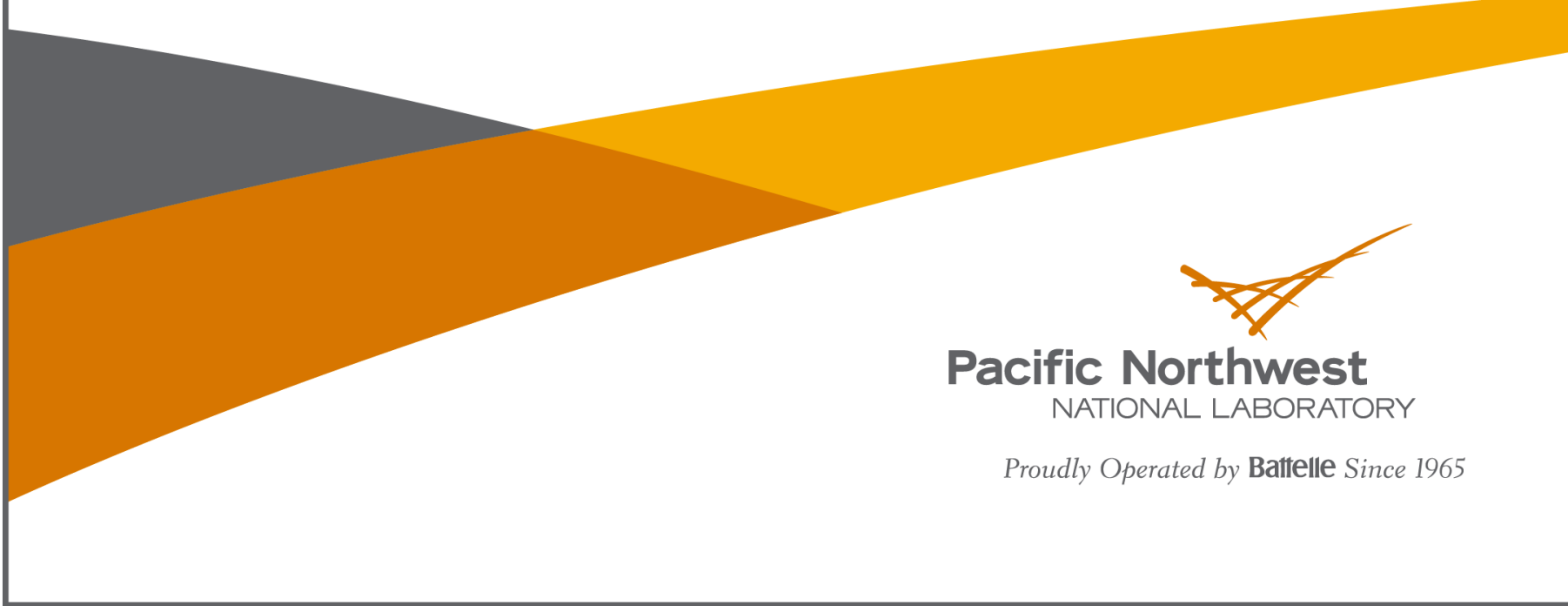




\title{
DISCLAIMER
}

This report was prepared as an account of work sponsored by an agency of the United States Government. Neither the United States Government nor any agency thereof, nor Battelle Memorial Institute, nor any of their employees, makes any warranty, express or implied, or assumes any legal liability or responsibility for the accuracy, completeness, or usefulness of any information, apparatus, product, or process disclosed, or represents that its use would not infringe privately owned rights. Reference herein to any specific commercial product, process, or service by trade name, trademark, manufacturer, or otherwise does not necessarily constitute or imply its endorsement, recommendation, or favoring by the United States Government or any agency thereof, or Battelle Memorial Institute. The views and opinions of authors expressed herein do not necessarily state or reflect those of the United States Government or any agency thereof.

\author{
PACIFIC NORTHWEST NATIONAL LABORATORY \\ operated by \\ BATTELLE \\ for the \\ UNITED STATES DEPARTMENT OF ENERGY \\ under Contract DE-AC05-76RL01830
}

Printed in the United States of America
Available to DOE and DOE contractors from the Office of Scientific and Technical Information,
P.O. Box 62, Oak Ridge, TN 37831-0062;
ph: (865) 576-8401
fax: $(865)$ 576-5728
email: reports@adonis.osti.gov

\begin{abstract}
Available to the public from the National Technical Information Service, U.S. Department of Commerce, 5285 Port Royal Rd., Springfield, VA 22161 ph: (800) 553-6847 fax: $(703) 605-6900$ email: orders@ntis.fedworld.gov online ordering: http://www.ntis.gov/ordering.htm
\end{abstract}

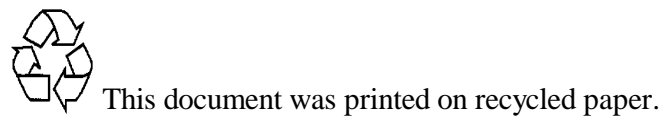




\title{
Majorana Demonstrator Bolted Joint Mechanical and Thermal Analysis
}

\author{
E Aguayo \\ DJ Reid \\ JE Fast
}

June 2012

Prepared for

the U.S. Department of Energy

under Contract DE-AC05-76RL01830

Pacific Northwest National Laboratory

Richland, Washington 99352 
PNNL-21510

\section{Executive Summary}

The MAJORANA DEMONSTRATOR is designed to probe for neutrinoless double-beta decay, an extremely rare process with a half-life in the order of $10^{26}$ years. The experiment uses an ultra-low background, high-purity germanium detector array. The germanium crystals are both the source and the detector in this experiment. Operating these crystals as ionizing radiation detectors requires having them under cryogenic conditions (below $90 \mathrm{~K}$ ). A liquid nitrogen thermosyphon is used to extract the heat from the detectors. The detector channels are arranged in strings and thermally coupled to the thermosyphon through a cold plate. The cold plate is joined to the thermosyphon by a bolted joint. This circular plate is housed inside the cryostat can. This document provides a detailed study of the bolted joint that connects the cold plate and the thermosyphon. An analysis of the mechanical and thermal properties of this bolted joint is presented. The force applied to the joint is derived from the torque applied to each one of the six bolts that form the joint. The thermal conductivity of the joint is measured as a function of applied force. The required heat conductivity for a successful experiment is the combination of the thermal conductivity of the detector string and this joint. The thermal behavior of the joint is experimentally implemented and analyzed in this study. 



\section{Acronyms and Abbreviations}

HPGe

MJD

PNNL

Pt RTD

OHFC

SI
High-purity germanium

MAJORANA DEMONSTRATOR

Pacific Northwest National Laboratory

Platinum resistive thermal device

Oxygen-Halogen Free Copper

International System of Units 



\section{Contents}

Executive Summary ...................................................................................................................................................iii Acronyms and Abbreviations .................................................................................................................................

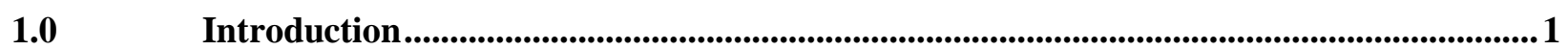

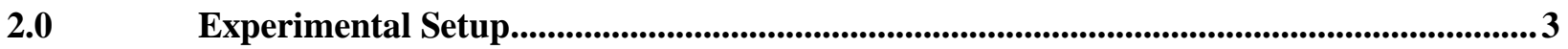

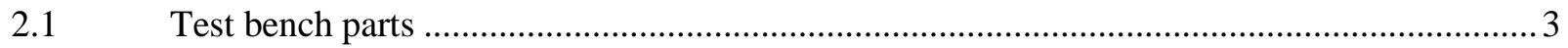

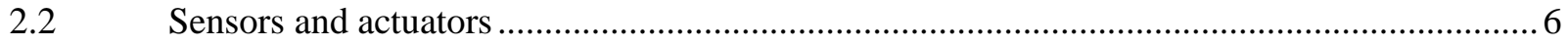

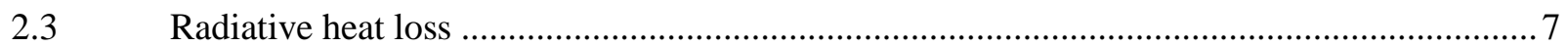

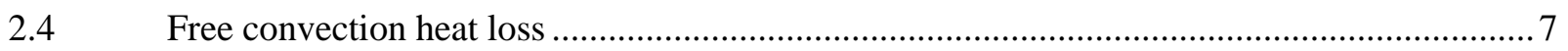

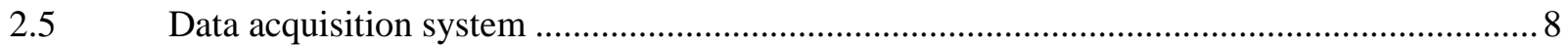

3.0 Mechanical analysis ............................................................................................................

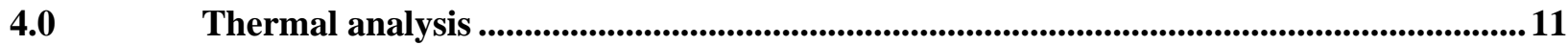

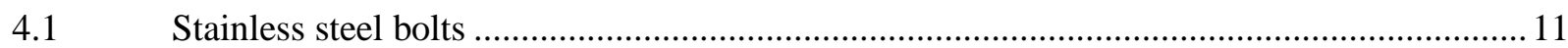

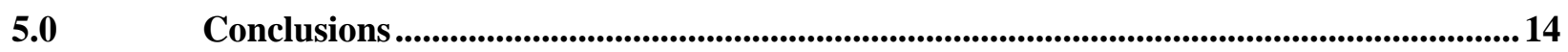

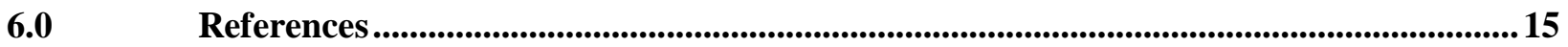



PNNL-21510

\subsection{Introduction}

The search for neutrinoless double-beta decay $(0 v \beta \beta)$ is of fundamental importance for physics (Elliott and Vogel 2002). One of the probes for this $0 v \beta \beta$ process is an experiment that exploits the process of double beta decay in ${ }^{76} \mathrm{Ge}$. Researchers at Pacific Northwest National Laboratory (PNNL) are part of the Majorana Collaboration that is conducting this MAJORANA DEMONSTRATOR ${ }^{76} \mathrm{Ge} 0 v \beta \beta$ experiment.

Although high-purity germanium (HPGe) detectors provide outstanding spectral resolution, the cryogenic cooling requirements (the detector needs to be kept at around $80 \mathrm{~K}$ or below) are critical to optimal performance. This requirement derives from the semiconductor physics of the detector crystal. If the temperature is not kept low enough, it is possible for a valence electron to gain sufficient thermal energy to be elevated across the band gap into the conduction band, effectively creating current in the crystal (Knoll 2000). In order to use a germanium crystal as a radiation detector, this current must be kept below a certain level to enable differentiating between the charge created from a physical radiation deposition and the inherent thermal noise of the semiconductor crystal. Commercially available HPGe systems are usually made out of a single crystal cooled with either a mechanical cooler or liquid nitrogen as a cryogen. The MAJORANA DEMONSTRATOR will operate seven strings of five crystals per module, with a total of two modules. This size of the lead background shield ( $1 \mathrm{~m}$ from the detector array to the cryogenic service body) requires a very efficient cooling system. A purely conductive cooler is limited by the thermal conductivity of its material (in the case of cooper, $400 \mathrm{~W} / \mathrm{mK}$ ). Thus, for this application, the purely conductive cooling approach is infeasible.

There are several contributors to the power budget of a germanium cryostat. Grouped by thermal mechanism of energy exchange, these are radiative (from the walls of the cryostat to the detector crystals), conductive (from the mechanical supports of the experiment and wires coming to the detector array) and lastly, dissipative (from the thermal energy dissipated by the biased transistor, immediately adjacent to the detector anode). For the radiative and conductive components of the power budget, careful design is critical. For example, having the thinnest wire possible (without degrading the performance of the detector channel) will mitigate the thermal short the wires create. A careful study of the power budget for the MAJORANA DEMONSTRATOR can be found in a previous PNNL report, Majorana Thermosyphon Prototype Experimental Results (Fast et al. 2010).

A horizontal thermosyphon was developed by our group and successfully tested for this application (Fast et al. 2010). This report documents the analysis of the thermal behavior of the bolted joint linking the horizontal thermosyphon and the detector array, supported by the cold plate. Figure 1 shows a rendering of a MAJORANA DEMONSTRATOR module. This figure shows, from left to right, the detector array inside the cryostat can, the cold plate bolted to the tip of the horizontal evaporator tube, and the vertical section leading to the condenser housed inside the Dewar. The right most tanks in the figure is the expansion tank that contains the load of nitrogen in the system when in the gas phase. Six bolts press the head of the thermosyphon against the cold plate, effectively thermally shorting these two surfaces. This document presents the measurements of the resistivity of this thermal joint. Section 2 presents the experimental setup, a mockup of the real system, with the sensors and actuator required for this experiment. Section 3 presents the test bench assembly procedure. Section 4 provides the experimental results. 


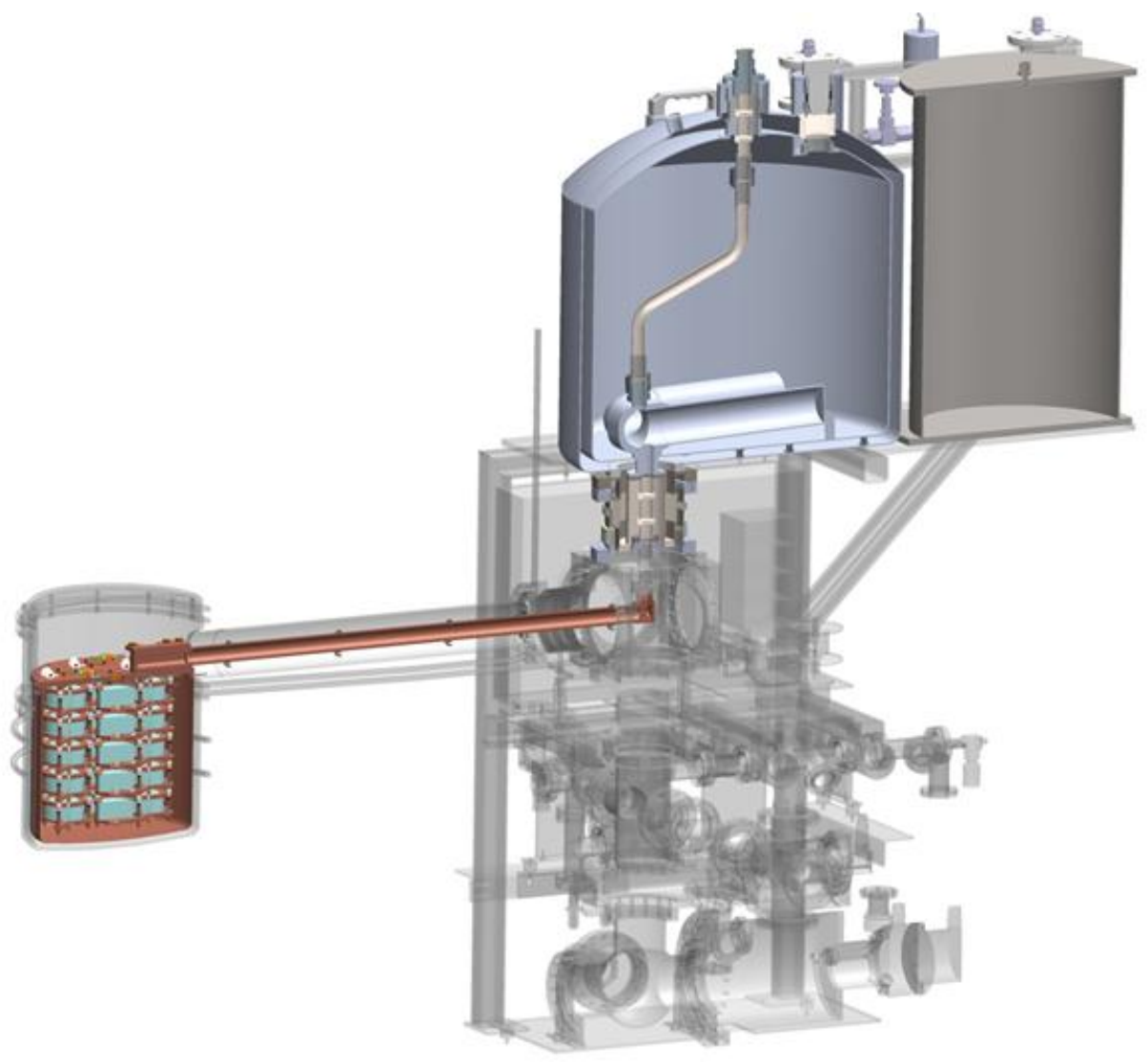

Figure 1: A MAJORANA DEMONSTRATOR module (shield not shown). The cryogenic system parts are shown in color. 
PNNL-21510

\subsection{Experimental Setup}

This section presents the experimental setup for the characterization of the thermal resistivity on a bolted joint and the mechanical parts that compose the system, as well as describing the sensors and actuators in the test bench. The test bench is a mockup of the MAJORANA DEMONSTRATOR interface from thermosyphon to cold plate, using parts made of OHFC copper. The thermosyphon and cold plate in the MAJORANA DEMONSTRATOR module will be made of electroformed copper. The electroforming process affects the thermal properties of the material, making it a better conductor and, using an etching process, the emissivity is also reduced. Therefore, the thermal results of experimenting with OHFC copper are applicable as a conservative estimate when applied to electroformed copper. The purpose of this experiment was to measure thermal resistivity of the bolted joint. To that end, a thermal gradient was created in the interface so that measuring the temperature across the joint allows a calculation of the thermal resistivity of the joint (see Section 4.0). In order to accomplish this, heat was generated in one end of the test bench by resistive heaters and sent into a heat sink formed by an ice bath at the other end of the test bench.

The heat measurements were conducted using a series of thermal sensors in the test bench. The first sensor was placed at the heat-source end of the test bench. The heat source is a resistor with a regulated voltage source, so the amount of heat can be adjusted. The heat entering the joint was measured using two temperature sensors along a machined path immediately adjacent to the heat source. The heat leaving the thermal joint was measured using the same machined thermal-path geometry and material as that used from the copper-to-copper joint to the heat sink. Two thermocouples, placed at each end of the thermal path to the ice bath, measured the outward flow of heat. This measurement will have the same predetermined tolerance as that of the heat entering the joint. The last component of the test bench is a heat sink, constructed using an ice-water bath, which provides a great deal of thermal capacity.

\subsection{Test bench parts}

As described, above, the parts that comprise the test bench are designed to create a thermal gradient in the bolted interface. This allows for accurate measurement of the heat going into the joint and that coming out of the joint. Figure 2 shows a model of the assembled test bench parts. The heat created in one end must be evacuated in the other end in order to create a measurable temperature gradient at the bolted interface. The way to measure the incoming heat and outgoing heat is to measure the temperature gradient in a known thermal path. Both arms of the test bench have identical thermal paths. Figure 3 shows the actual parts in the laboratory bench prior to assembly. 


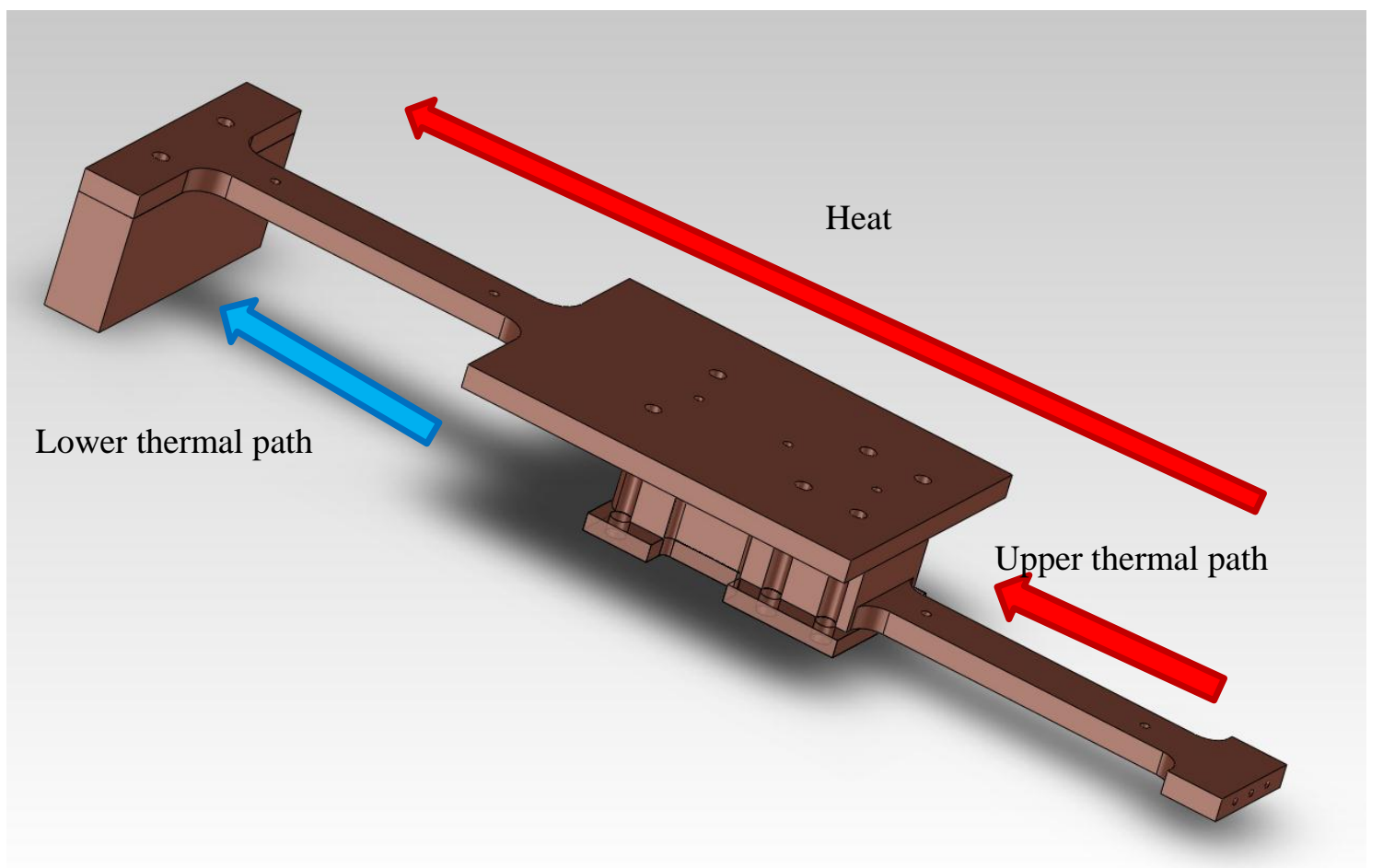

Figure 2: Solidworks model of bolted joint thermal test bench

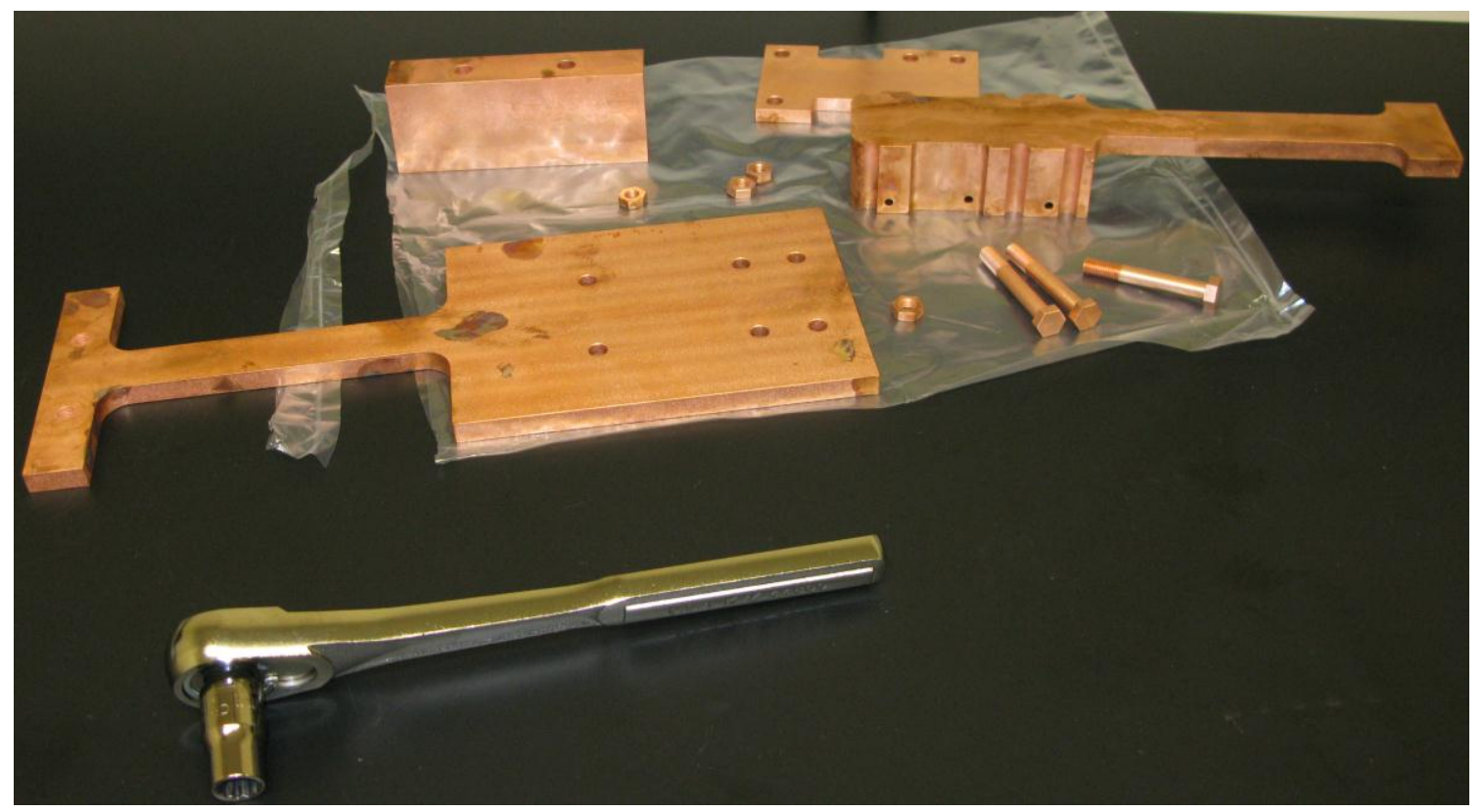

Figure 3: Test bench components before assembly

For this thermal measurement, care must be taken that the parts that make up the test bench reach thermal equilibrium by the time of the measurements. This time-to-equilibrium is dictated by the thermal capacity of each one of the parts, and is directly proportional to the masses of each part. In the SI, heat capacity is expressed in units of joules per Kelvin $\left(\mathrm{J} /\right.$ *K$\left.^{\mathrm{K}}\right)$. For this experiment, the time that it takes to heat each part 
so that the system reaches equilibrium can be computed using Equation 1 below. For copper, the heat capacity at room temperature and constant pressure is $0.385 \mathrm{Jg}^{-1} \mathrm{~K}^{-1}$ [De Leon, 2012]. Conventionally, one would assume a temperature increase of each part of the assembly by the same amount, for example $20 \mathrm{~K}$. However, this does not correspond to our test bench, since there will be a temperature gradient across the assembly. The same calculation could be done for the time that it will take to cool each part of the assembly. Since the amount of heat supplied to the system via the resistive heaters can be measured accurately, the maximum time to thermal equilibrium is derived using this quantity. Table 1 presents the result of this calculation. For each part, the time to attain a $20 \mathrm{~K}$ temperature difference is calculated, applying three different wattages to the test bench. When applying $10 \mathrm{~W}$, the time to a $20 \mathrm{~K}$ difference is under 1 hour; at the other extreme, when $30 \mathrm{~W}$ are applied, it takes less than 10 minutes to bring the whole system to an equilibrium temperature.

$$
C_{p}=\frac{\text { Pinput } * \text { Time }}{m * \Delta T}
$$

Table 1: Calculated Time to Thermal Stability in the Test Bench for Three Different Values of Input Power

\begin{tabular}{|c|c|c|c|c|}
\hline Part & Mass (g)[lbs.] & $\begin{array}{c}\text { Time (s) Pinput }= \\
\text { 10W }\end{array}$ & $\begin{array}{c}\text { Time (s) Pinput }= \\
\text { 20W }\end{array}$ & $\begin{array}{c}\text { Time (s) Pinput }= \\
\text { 30W }\end{array}$ \\
\hline Test Plate & $2667[5.88]$ & 2053 & 1026 & 684 \\
\hline Cold plate interface & $2019[4.45]$ & 1554 & 777 & 518 \\
\hline Clamp plate & $462[1.02]$ & 355 & 177 & 118 \\
\hline Base plate & $1406[3.10]$ & 1082 & 541 & 360 \\
\hline Total & 6554 & 5046 & 2523 & 1682 \\
\hline
\end{tabular}

Table 2: Selected parameters used in the calculation of the heat budget presented in 
PNNL-21510

Table 8

\begin{tabular}{|c|c|c|}
\hline $\begin{array}{c}\text { Test bench } \\
\text { Component }\end{array}$ & $\begin{array}{c}\text { Characteristic } \\
\text { length }(\mathrm{m})\end{array}$ & Area $\left(\mathrm{m}^{2}\right)$ \\
\hline Body & 0.173 & 0.04325 \\
\hline Upper arm & 0.102 & 0.00408 \\
\hline Lower arm & 0.102 & 0.00408 \\
\hline
\end{tabular}

\subsection{Sensors and actuators}

Six temperature sensors and three resistive heaters are used in the thermal test bench. The thermal sensor used in this experiment is a platinum thin-film resistive thermal device (Pt RTD) manufactured by Sensor Scientific, Inc. Platinum RTDs feature a stable output over a long period of time, ease of recalibration, and accurate readings over narrow temperature spans. Disadvantages, when compared to thermocouples, are their smaller overall temperature range, higher initial cost, and less durability. Its dimensions are $2.3 \mathrm{~mm}$ long, $2.1 \mathrm{~mm}$ wide, and $0.9 \mathrm{~mm}$ high. The manufacturer warns that if elements are encapsulated in a potting compound, one must make sure the compound does not induce pressure loads, which would result in a strain-gauge effect. The response time for this thermal sensor is reported by the manufacturer to be a maximum of 10 seconds; the elements have a resistance of $1000 \Omega$ at $0^{\circ} \mathrm{C}$. The lead wires used to connect the RTD to a readout system can contribute to measurement error; thus, a cross-calibration of all the Pt RTDs with the lead wires soldered must be carried out before experimentation.

The upper copper bar is fitted with two RTDs, as is the lower bar, which extends into the heat sink (ice water bath). The RTDs are located such that the temperature difference (in Kelvin) is equal to the heat flow in Watts; i.e., the bar cross section and length are chosen to give a thermal resistance of $1 \mathrm{~K} / \mathrm{W}$ between these measurements.

Equation 2 (Incropera, 2007) shows the relationship between temperature difference and heat flow across a conductive heat path.

$$
\mathrm{Q}=\frac{\mathrm{k} * \Delta \mathrm{T} * \mathrm{~A}}{\mathrm{~L}}
$$

Where;

$$
\begin{aligned}
& q \text { is the heat flow }(\mathrm{W}) \\
& k \text { is the thermal conductivity }(\mathrm{W} / \mathrm{m}-\mathrm{K}) \\
& A \text { is the area of the heat exchange surface }\left(\mathrm{m}^{2}\right) \\
& L \text { is the length of the heat exchange volume (m) }
\end{aligned}
$$


PNNL-21510

$\Delta T$ is the temperature difference of the two exchanging heat elements $(\mathrm{K})$

For the joint heat path, where the heat entering the test bench and that exiting it are measured, the parameters have the following values:

- A cross sectional arm $=0.4 \mathrm{in}^{2}=2.58 \times 10^{-4} \mathrm{~m}^{2}$

- $\mathrm{L}$ arm $=4.0$ in $=0.102 \mathrm{~m}$

- $\mathrm{K}$ arm $=394 \mathrm{~W} / \mathrm{mK}$

- $\Delta \mathrm{T} / \mathrm{Q}=\mathrm{L} /(\mathrm{KA})=0.102 /\left(394 * 2.58 \times 10^{-4}\right)=1.0 \mathrm{~K} / \mathrm{W}$

\subsection{Radiative heat loss}

The expected radiative heat leakage out of the system can be calculated using the surface of the test bench and the emissivity of the materials deployed in the setup. Equation 3 shows the relationship between the flow of energy radiated from a hot body to a colder body for a heat-exchange surface area A and temperatures $\mathrm{T}_{\mathrm{h}}$ and $\mathrm{T}_{\mathrm{c}}$, respectively.

$$
\mathrm{q}=\varepsilon \sigma\left(\mathrm{T}_{\mathrm{h}}{ }^{4}-\mathrm{T}_{\mathrm{c}}{ }^{4}\right) \mathrm{A}_{\mathrm{c}}
$$

Where;

$$
\begin{aligned}
& T_{h} \text { is the hot body absolute temperature }(\mathrm{K}) \\
& T_{c} \text { is the cold body (surroundings) absolute temperature (K) } \\
& A_{c} \text { is the area of the object }\left(\mathrm{m}^{2}\right) \\
& \sigma \text { is Boltzman's constant }\left(5.67 * 10^{-8} \mathrm{~W} / \mathrm{m}^{2}-\mathrm{K}^{4}\right) \\
& \varepsilon \text { is the emissivity of the object. }(0.12 \text { for copper) }
\end{aligned}
$$

\subsection{Free convection heat loss}

The test bench is operated at room temperature. The convection of the relatively warm ambient air surrounding the test bench is a heat path that must be taken into account during experimentation. The rate of free convection from the surfaces exposed to air of the test bench is given by Newton's law of cooling:

$$
\mathrm{Q}=\mathrm{h}_{\mathrm{c}} \mathrm{A} \Delta \mathrm{T}
$$

The convective conductance, $h_{c}$, may be obtained from the Rayleigh number:

$$
\mathrm{Ra}_{\mathrm{L}}=\mathrm{g} \beta \Delta \mathrm{T} \mathrm{L}^{3} / \alpha v
$$

All gas properties must be evaluated at the air film temperature, which is assumed to be the room temperature during experimentation $\left[\mathrm{T}_{\mathrm{f}}=\left(\mathrm{T}_{\text {bench }}-323\right) / 2 \mathrm{~K}\right]$ (Incropera et al. 2007, 537). Equation 5 parameters used in this calculation are listed in Table 3. 
Table 3: Selected parameters used in the Rayleigh number calculation for the joint test bench system. From (Incropera et al. 2007, 537).

\begin{tabular}{|l|l|l|}
\hline Parameter & Description & Value \\
\hline$\beta=1 / \mathrm{T}_{\mathrm{f}}$ & Expansion coefficient & $0.11 / \mathrm{K}$ \\
\hline $\mathrm{L}$ & Characteristic length of the system & $52.5 \mathrm{~cm}$ \\
\hline$\alpha$ & Thermal diffusivity of air @ $323 \mathrm{~K}$ & $25 \times 10^{-6} \mathrm{~m}^{2} / \mathrm{s}$ \\
\hline$v$ & Kinematic viscosity of air @ $323 \mathrm{~K}$ & $17.5 \times 10^{-6} \mathrm{~m}^{2} / \mathrm{s}$ \\
\hline $\operatorname{Pr}$ & Prandtl number & 0.7 \\
\hline
\end{tabular}

Values of $\mathrm{Ra}_{\mathrm{L}}<10^{9}$ are characteristic of laminar flows. All the computed values for the Rayleigh numbers of the test bench are below this threshold. The appropriate correlation between Rayleigh and Nusselt number must be used (Incropera et al. 2007, p. 535):

$$
N u_{L}=0.68+\frac{0.67 R a_{L}{ }^{1 / 4}}{\left[1+(0.492 / P r)^{9 / 16}\right]^{4 / 9}}
$$

\subsection{Data acquisition system}

The data acquisition system used is based on a Keithley 2701 with a 7008 expansion card. This apparatus is controlled via an Ethernet port by an application written in C. Seven channels were connected in fourwire mode to each of the RTDs. The RTDs used in this experiment had a nominal resistance of $1 \mathrm{k} \Omega$ at $0^{\circ} \mathrm{C}$. The 2701 does not have a built-in function to handle these devices, so the apparatus was configured to read out the resistance measurements, which were then converted to temperature using the manufacturer's calibration equation. 


\subsection{Mechanical analysis}

The methods used to assemble the test bench, and in particular the torque applied to the bolts, have a significant effect on the results of the experimentation. In the initial practice assembly, copper bolts were used without any lubrication. The bolts quickly fused to the nuts and the assembly had to be discontinued. Figure 4 shows the state of the copper bolts after this first attempt to assemble the test setup. Both the bolts and the nuts showed significant damage in the threads.

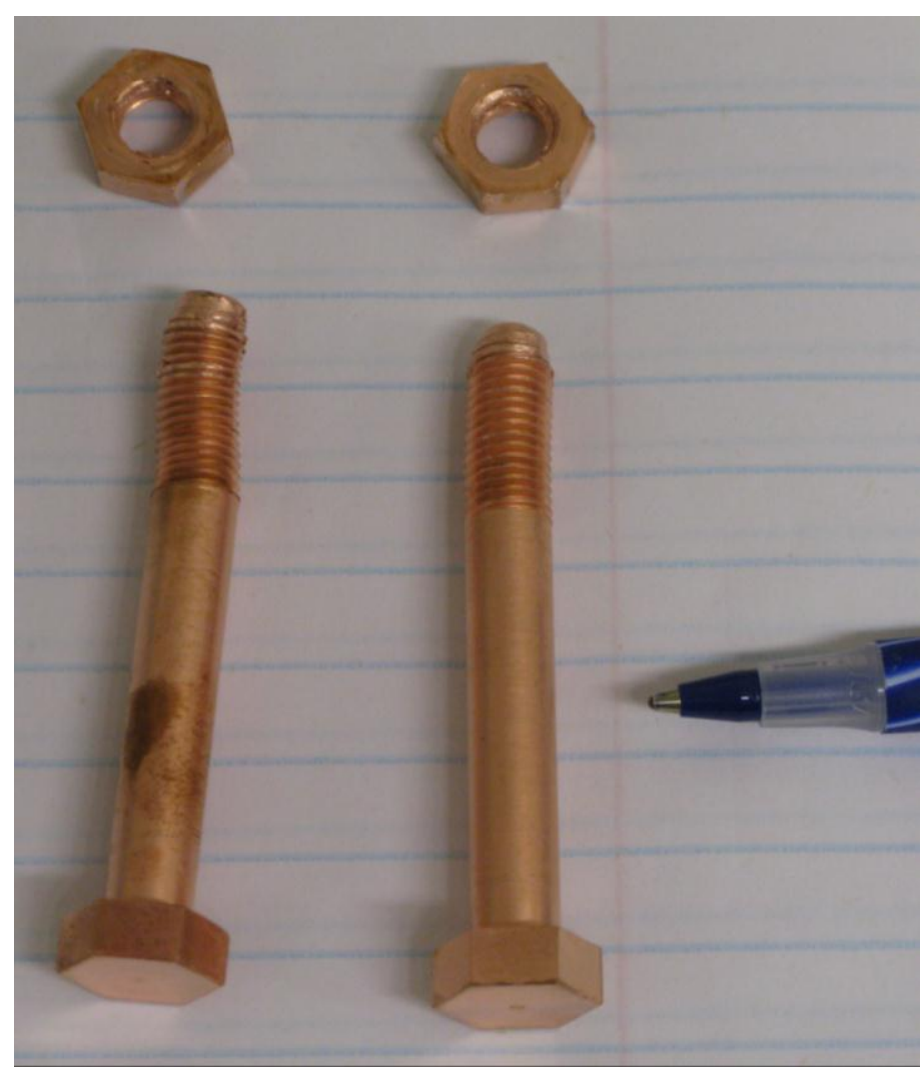

Figure 4: Copper bolts after first assembly attempt

After the failed first assembly attempt, the copper bolts and nuts were replaced with stainless steel bolts and nuts. The results presented in Section 4.0 were acquired using these steel bolts. The torque applied to the stainless steel bolts was $150 \mathrm{in}-\mathrm{lb}$. The torque for the cooper bolts for the final experiment has yet to be determined. Pressure film and various bolt torques were applied to study the contact properties of the test setup. Figure 5 shows the pressure film reading after the assembly of the test setup using $200 \mathrm{in}-\mathrm{lb}$ on the bolts. The pressure film shows how the edges of the contact surface, close to the bolts, make contact, whereas the center of the contact surface, further away from the bolts, shows no contact. 


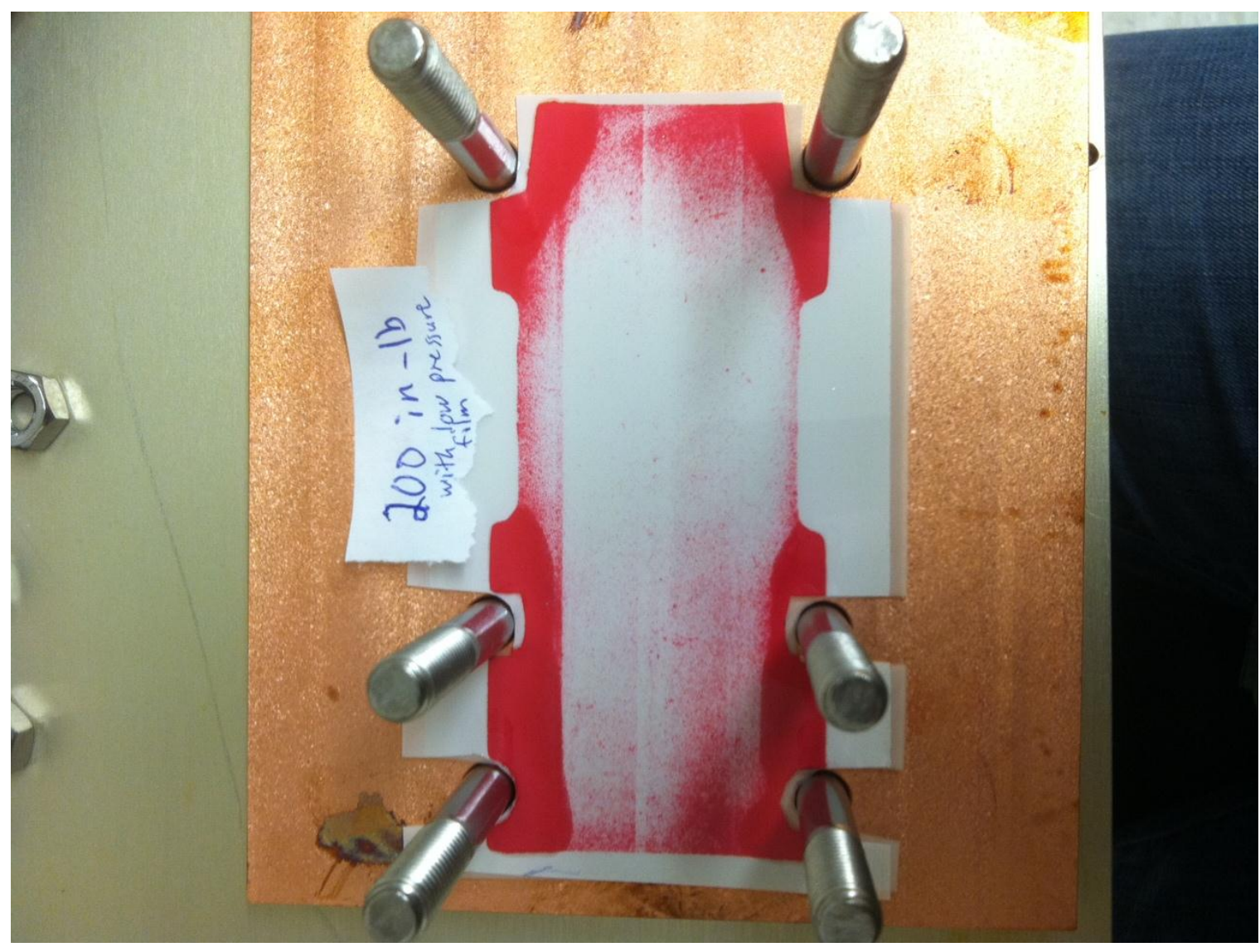

Figure 5: Contact surface with torque 200 in-lb using stainless steel bolts 


\subsection{Thermal analysis}

There are three independent measures of heat flow. The first is the measurement of voltage and current applied to the resistors (heaters). Measurements were taken at 10,20, and $30 \mathrm{~W}$. The two pair of RTD measurements (T1-T2 and T5-T6) provide independent readings of heat flow in the upper and lower copper bars, i.e., on either side of the bolted joint. The system was allowed to come to equilibrium over several hours prior to taking these measurements, so, in principle, these are steady state readings.

\subsection{Stainless steel bolts}

Table 4 provides the results of the experiments using the test bench settings described in Section 3.0. For three different applied heats, a measurement of the heat conduction in the upper and lower arms is derived using the reading of the thermal sensors.

Table 4: Heat Measurements at The Two Thermal Paths on the Test Bench Using Three Wattages

\begin{tabular}{|c|c|c|}
\hline Power supply Load (W) & Upper arm heat load (W) & Lower arm heat load (W) \\
\hline $\mathbf{1 0}$ & 9.0 & 4.8 \\
\hline $\mathbf{2 0}$ & 17.8 & 11.2 \\
\hline $\mathbf{3 0}$ & 28.4 & 19.8 \\
\hline
\end{tabular}

From these measurements one can see that heat is clearly exiting the system between the heaters and the cold sink. There are three possible explanations. The first is that heat is flowing into the surrounding air by convection; the second is that heat is radiating from the fixture; and the third is that the system is not yet in a steady state and heat is still warming the bulk copper. This last supposition is discarded in light of the data presented in Table 1. The second, radiative heat, can only explain up to 7\% of the heat loss. The most likely cause of heat loss is therefore free convection around the test fixture. While this large discrepancy of heat flow results in a large uncertainty in the joint thermal resistance, the joint resistance observed is sufficiently small that this error is inconsequential at this time. However, it may become a significant issue in future testing if the joint resistivity becomes significant.

Tables 5, 6 and 7 below present the observed temperatures for the three test runs. RTDs T1 and T2 were used to measure the heat flow in the upper copper bar; T5 and T6 in the lower bar; and T3 and T4 read each side of the bolted joint to assess the joint thermal resistivity. In all cases, the temperature drop across the joint was less than $0.1 \mathrm{~K}$. There appears to be a trend that the resistance of the joint drops with higher heat loads, but this cannot be confirmed given the precision of the instrumentation. Table 8 shows the comparison of the calculated components of the heat budget of the experiment and the measured heat components. The difference between calculated and measured heat loads agree within a $10 \%$ in the worst case. 
Table 5: Thermocouple Readings after 5000 Seconds at $10 \mathrm{~W}$

\begin{tabular}{|c|c|c|c|}
\hline Thermocouple & Resistance $(\mathbf{k} \boldsymbol{\Omega})$ & Temperature (C) & Temperature (K) \\
\hline T1 & $1.1311( \pm 1 \%)$ & 33.73 & 306.88 \\
\hline T2 & $1.0962( \pm 1 \%)$ & 24.70 & 297.85 \\
\hline T3 & $1.0836( \pm 1 \%)$ & 21.45 & 294.60 \\
\hline T4 & $1.0833( \pm 1 \%)$ & 21.38 & 294.53 \\
\hline T5 & $1.0667( \pm 1 \%)$ & 17.10 & 290.25 \\
\hline T6 & $1.0482( \pm 1 \%)$ & 12.35 & 285.50 \\
\hline
\end{tabular}

Table 6: Thermocouple Readings After 7550 Seconds at $20 \mathrm{~W}$

\begin{tabular}{|c|c|c|c|}
\hline Thermocouple & Resistance $(\mathbf{k} \boldsymbol{\Omega})$ & Temperature $(\mathbf{C})$ & Temperature (K) \\
\hline T1 & $1.2188( \pm 1 \%)$ & 56.46 & 329.61 \\
\hline T2 & $1.1503( \pm 1 \%)$ & 38.68 & 311.83 \\
\hline T3 & $1.12925( \pm 1 \%)$ & 33.235 & 306.385 \\
\hline T4 & $1.12918( \pm 1 \%)$ & 33.215 & 306.365 \\
\hline T5 & $1.1007( \pm 1 \%)$ & 22.87 & 299.02 \\
\hline T6 & $1.0457( \pm 1 \%)$ & 11.71 & 284.86 \\
\hline
\end{tabular}

Table 7: Thermocouple Readings after 7000 Seconds at $30 \mathrm{~W}$

\begin{tabular}{|c|c|c|c|}
\hline Thermocouple & Resistance $(\mathbf{k} \Omega)$ & Temperature $(\mathbf{C})$ & Temperature (K) \\
\hline T1 & $1.3177( \pm 1 \%)$ & 82.30 & 355.45 \\
\hline T2 & $1.2090( \pm 1 \%)$ & 53.93 & 327.08 \\
\hline T3 & $1.1774( \pm 1 \%)$ & 45.67 & 318.82 \\
\hline T4 & $1.1773( \pm 1 \%)$ & 45.66 & 318.81 \\
\hline T5 & $1.1370( \pm 1 \%)$ & 35.24 & 308.39 \\
\hline T6 & $1.06034( \pm 1 \%)$ & 15.48 & 285.63 \\
\hline
\end{tabular}


Table 8: Heat Budget for Each Experimental Run

\begin{tabular}{|c|c|c|c|c|c|c|c|c|}
\hline \multirow{2}{*}{$\begin{array}{c}\text { Applied } \\
\text { power } \\
\text { (W) }\end{array}$} & \multicolumn{3}{|c|}{ Radiative heat loss (W) } & \multicolumn{3}{|c|}{ Free convection heat loss (W) } & \multirow{2}{*}{$\begin{array}{l}\text { Calculated } \\
\text { heat loss } \\
\text { (W) }\end{array}$} & \multirow{2}{*}{$\begin{array}{c}\text { Measured } \\
\text { heat loss } \\
\text { (W) }\end{array}$} \\
\hline & $\begin{array}{c}\text { Upper } \\
\text { Arm }\end{array}$ & $\begin{array}{l}\text { Lower } \\
\text { arm }\end{array}$ & Body & $\begin{array}{c}\text { Upper } \\
\text { Arm }\end{array}$ & $\begin{array}{l}\text { Lower } \\
\text { arm }\end{array}$ & Body & & \\
\hline 10.0 & 0.224 & 0.066 & 0.340 & 0.844 & 0.234 & 2.892 & 4.602 & 4.2 \\
\hline 20.0 & 0.304 & 0.066 & 0.494 & 1.100 & 0.844 & 3.917 & 6.728 & 6.6 \\
\hline 30.0 & 0.116 & 0.072 & 0.659 & 1.212 & 0.940 & 5.580 & 8.581 & 8.6 \\
\hline
\end{tabular}




\subsection{Conclusions}

Initial testing of the test-bench thermal joint, crafted to represent the cold plate-to-thermosyphon joint in the MAJORANA DEMONSTRATOR, using stainless steel bolts torqued to $150 \mathrm{in}-\mathrm{lb}$ indicates very low thermal resistance $(<0.1 \mathrm{~K} / \mathrm{W})$. Large heat leaks to the environment and/or very long settling time (heat working to change bulk copper temperatures) limit accuracy to $\sim 30-50 \%$. This may become an issue if further tests with realistic bolt torque forces using coated copper bolts result in larger temperature drops across the bolted joint interface. 
PNNL-21510

\subsection{References}

Elliott, SR, and P Vogel. 2002. "Double Beta Decay." Annual Review of Nuclear and Particle Science 52:115-51. 10.1146/annurev.nucl.52.050102.090641.

Fast, JE, DJ Reid, and E Aguayo-Navarrete. 2010. Majorana Thermosyphon Prototype Experimental Results Report No. PNNL-20065, Pacific Northwest National Laboratory, Richland, WA.

Incropera, FP, DP Dewitt, TL Bergman, and AS Lavine. 2007. Introduction to Heat Transfer. John Wiley and Sons, Inc., Hoboken, NJ.

N. De Leon, http://www.iun.edu/ cpanhd/C101webnotes/matter-and-energy/specificheat.html (Last accessed on 06/07/2012)

Knoll, GF. 2000. Radiation Detection and Measurement. 3rd ed., Wiley, New York. 


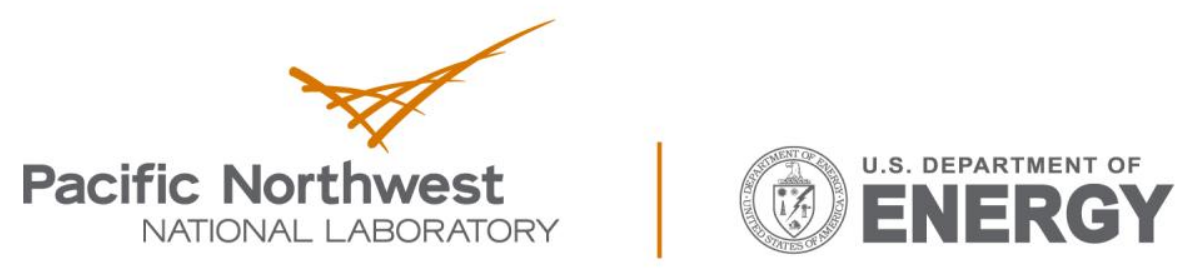

Proudly Operated by Battelle Since 1965

902 Battelle Boulevard

P.O. Box 999

Richland, WA 99352

1-888-375-PNNL (7665)

www.pnnl.gov 